\title{
Pigment Identification, Raman Microscopy and the Arts/Science Interface : A Tribute to Walter McCrone
}

\author{
Robin J. H. Clark \\ Christopher Ingold Laboratories, University College London, London WC1H 0AJ, UK
}

Raman microscopy (RM) is now established as one of the key techniques for the identification of pigments on works of art, mainly because of its spatial $(\leq 1 \mu \mathrm{m})$ and spectral $\left(\leq 1 \mathrm{~cm}^{-1}\right)$ resolution, its specificity, its excellent sensitivity by way of modern CCD detectors, and the fact that it may be applied to an object in situ, i.e. without the need for sampling[1,2]. Important knowledge may be gained on manuscripts, paintings, pottery, china, enamels, faience, papyri, icons, polychromes and the other artwork forming the basis of our cultural heritage. In particular, pigment degradation processes may be probed, understood, halted and possibly reversed through information gained by RM. Pigment information, now available as libraries of Raman spectra of the common pigments and dyes[3,4], may also provide clues to early pigment trade routes and bases for the authentication of artwork. Recent studies on a rich variety of extremely valuable items will be described.

1. Black Pigments Black materials, albeit of high scattering efficiency, may yield only exceedingly weak spectra due to their high absorbance, yet their identification and that of their degradation products are of great importance to the art world. The blackening of lead white, $2 \mathrm{PbCO}_{3} \cdot \mathrm{Pb}(\mathrm{OH})_{2}$ on illuminated manuscripts can arise either from oxidation by atmospheric oxidants to form plattnerite $\left(\mathrm{PbO}_{2}\right)$, or from reaction with certain contiguous sulphide pigments or with atmospheric or microbe-generated hydrogen sulphide $\left(\mathrm{H}_{2} \mathrm{~S}\right)$ to form galena $(\mathrm{PbS})[5-7]$. The highly efficient Raman systems now available make it possible to obtain Raman spectra of most black materials, e.g. PbS in situ on the Jamnitzer Manuscript at the V\&A Museum[6] and carbon black on many manuscripts through its broad Raman bands at c. 1350 and $1580 \mathrm{~cm}^{-1}$, characteristic of disordered and ordered graphite, respectively.

2. White Pigments By contrast with the above, many white pigments - notably the widely used industrial pigment anatase $\left(\mathrm{TiO}_{2}\right)$ - are excellent Raman scatterers. The mineral form of this pigment is usually black, dark grey, indigo or brown, but the synthetic form could only be produced pure and white from c. 1923: as such this is a useful datemarker for artwork. Thus a series of papyri supposedly dating from c. $1250 \mathrm{BC}$ were shown to be illuminated with white anatase; this observation, taken in conjunction with the identification of six other modern pigments on the papyri, readily made it clear that the latter were $20^{\text {th }}$ century products[8].

3. Major Manuscripts The King George III copy of the Gutenberg Bible, held in the British Library, has been analysed to determine that the palette comprises vermilion, lead tin yellow (type 1), carbon black, azurite, malachite, verdigris, chalk, gypsum and lead white. This is in agreement with the pigments suggested to have been used by the accompanying model books which describe the method used for its illumination. The palette of this Gutenberg Bible is shown to be similar to those of the Gutenberg Bibles held at Lambeth Palace (London) and Eton College (Windsor)[9]. Studies on the Lindisfarne Gospels (valued at $£ 25 \mathrm{~m}$ ) reveal that the key blue pigment thereon is indigo, not lapis lazuli as previously believed, a result which radically changes conventional thinking as to when trade routes to Britain from Afghanistan were first established. 
4. Icons and Polychromes The combined application of Raman microscopy and laser-induced breakdown spectroscopy has proved to be very effective for the identification of pigments at different depths below the surfaces of icons and polychromes[10-12]. Recent studies of a $19^{\text {th }}$ century Russian icon revealed the identities of the pigments in the upper layers to be white lead, zinc oxide (used for repair purposes), vermilion and red lead above a silver foil; below this was found the white ground which consists of a mixture of gypsum and anhydrite, immediately above the wood.

5. Genuine and Forged or Reproduction postage Stamps The rare and valuable Hawaiian Missionary stamps dating from 1851 have been shown by RM to have been printed with an ink composed of Prussian blue. The blue particles (optical brighteners) dispersed within the paper fibres of the stamps were shown to be lazurite or ultramarine blue (its synthetic equivalent)[13]. Each cancellation or postmark is composed of carbon, vermilion, iron(III) oxide or a madder-like organic dye. The usage of these pigments on the genuine stamps differs in subtle but usually definable ways from that of forged copies produced in the $20^{\text {th }}$ century. Reproduction stamps have different pigments altogether, indicating the importance - largely yet to be realised - of RM to philately.

6. The Vinland Map and Walter McCrone The Vinland Map[14] is a world map on parchment. From cartographical, paleological and philological analyses the map appears to date from c. 1440, yet it includes representations of Iceland, Greenland and the north-eastern seaboard of North America ("Vinland"). It thus appears to predate Columbus's discovery of America by c. 50 years. Walter McCrone's key discovery by polarised light microscopy (PLM) was that the pale yellow edges to the black lines defining the map contain almost pure anatase of a particle size and size distribution (c. $0.15 \mu \mathrm{m}$ ) characteristic of synthetic $\mathrm{TiO}_{2}$, i.e. it is a post 1920 material. This controversial result has been challenged by PIXE and ${ }^{14} \mathrm{C}$ radiocarbon studies (albeit these pertain only to the parchment), but confirmed by RM. McCrone's staunch and emphatic defence of PLM as an analytical technique was his hallmark and we all owe him a great debt in this respect[15].

\section{References}

[1] R. J. H. Clark, Chem. Soc. Rev. 24, (1995) 187.

[2] G. D. Smith and R. J. H. Clark, Rev. Conserv. Sci. 2, (2002) 92.

[3] I. M. Bell et al., Spectrochim. Acta 53A, (1997) 2159.

[4] L. Burgio and R. J. H. Clark, Spectrochim. Acta 57A, (2001) 1491.

[5] L. Burgio et al., Analyst 126, (2001) 222.

[6] G. D. Smith et al., Stud. Conserv. 47, (2002) 250.

[7] G. D. Smith et al., J. Appl. Phys. 92, (2002) 4375.

[8] L. Burgio and R. J. H. Clark, J. Raman Spectrosc. 31, (2000) 495.

[9] T. D. Chaplin et al., in preparation.

[10] L. Burgio et al., Appl. Spectrosc. 54, (2000) 463.

[11] L. Burgio et al., Spectrochim. Acta B56, (2001) 905.

[12] Sister Daniilia et al., J. Raman Spectrosc. 33, (2002) 807.

[13] T. D. Chaplin et al., J. Raman Spectrosc. 33, (2002) 424, and unpublished work.

[14] K. L. Brown and R. J. H. Clark, Anal. Chem. 74, (2002) 3658, and unpublished work.

[15] I am very grateful to my associates on this work, most recently Drs K. L. Brown, L. Burgio, T. D. Chaplin, S. Firth and G. D. Smith, and to the EPSRC for financial support. 